\title{
Social Relationships and Group Dynamics Inside a Community Correction Facility for Women
}

International Journal of Offender Therapy and

Comparative Criminology 2016, Vol. 60(9) 1016-1035

(C) The Author(s) 2015

Reprints and permissions: sagepub.com/journalsPermissions.nav DOI: $10.1177 / 0306624 X 15591805$ ijo.sagepub.com

@SAGE

\section{Andrea Cantora', Jeff Mellow ${ }^{2}$, and Melinda D. Schlager ${ }^{3}$}

\begin{abstract}
This article presents research on women's perceptions and experiences residing in a female community correction facility. Qualitative interview data and field observations are used to examine resident relationships, perceptions of on-site group treatment, and benefits of receiving off-site treatment. Findings from this study indicate an overwhelming feeling of tension and lack of trust among residents, resulting in most women withdrawing from social interactions. Relationship dynamics also played a role in women's participation during on-site group treatment and desiring offsite treatment. This study supports the need to create, and sustain, therapeutic environments within community correction settings for women.
\end{abstract}

\section{Keywords}

women offenders, community corrections, group treatment, rehabilitation, qualitative research

\section{Introduction}

Group treatment is the most common method for engaging criminal justice populations in need of treatment (e.g., 12 steps and other mutual-help groups, cognitivebehavioral therapy, and therapeutic community [TC] models). Its popularity is based

\footnotetext{
University of Baltimore, MD, USA

${ }^{2}$ John Jay College of Criminal Justice, New York City, NY, USA

${ }^{3}$ Caruth Police Institute; University of North Texas, TX, USA
}

\section{Corresponding Author:}

Andrea Cantora, Assistant Professor, School of Criminal Justice, College of Public Affairs, University of Baltimore, I420 N. Charles Street, Baltimore, MD 2120I, USA.

Email: acantora@ubalt.edu 
on a number of factors: (a) The cost of group treatment is usually less than individuallevel therapy, (b) research indicates it is as effective as one-on-one treatment (McRoberts, Burlingame, \& Hoag, 1998), and (c) it can provide a safe environment, which fosters mutual support, assistance, trust, and feedback from one's peer group (DeLeon, 1995). In the correctional rehabilitation field, cognitive-behavioral group approaches are the most effective strategy (Andrews \& Bonta, 2010). For women offenders, gender-responsive strategies designed to address women-specific issues in a group setting are becoming increasingly popular (Gehring, Van Voorhis, \& Bell, 2010; Messina, Grella, Cartier, \& Torres, 2010; Wright, Van Voorhis, Salisbury, \& Bauman, 2009).

Understanding what works best for specific populations is necessary for providing effective treatment and for producing successful outcomes. Part of understanding what works involves assessing intra-dynamics of a group treatment environment. Much of the research on treatment environment is highlighted in the substance abuse and gender-responsive literature. Both literatures are discussed in this article, with a specific focus on therapeutic relationships and engagement within the group context. The literature on peer relationships within female prisons is also discussed to provide further context. The current study presented examines the specific context of a female community correction setting that incorporates group treatment. Resident relationships and perceptions of on-site and off-site group treatment are discussed.

\section{The Nature of Women's Prison Relationships}

The study of social relationships in female prisons has been examined since the 1960s. Themes from early studies provide a portrayal of women's prisons as homelike, supportive, and consisting of strong pseudo-kinship ${ }^{1}$ relationships (Giallombardo, 1966; Ward \& Kassebaum, 1965). Also common were intimate sexual relationships among inmates (Giallombardo, 1966; Jones, 1993; Owen, 1998; Propper, 1982; Ward \& Kassebaum, 1965). Research from the past 15 years indicates similarities but also points to a shift in relationship dynamics among female inmates.

Several qualitative studies examining women's social relationships find women in prison struggle to develop supportive relationships with others due to their inability to trust (Einat \& Chen, 2012; Greer, 2000; Kruttschnitt, Gartner, \& Miller, 2000; Severance, 2005). In Severance's (2005) study, participants described feeling uncomfortable talking openly with other inmates due to gossiping. Participants were also suspicious of other women after observing women stealing personal items. Regardless, some women developed friendships with others based on common backgrounds, work assignments, or living areas. Although some relationships did exist, Severance (2005) and Greer (2000) failed to find support for pseudo-kinships.

Einat and Chen (2012) further found that gossip increases the social conflict, weakens the settings' cohesive dynamics, creates inequality among women, isolates them, and may cause psychological harm. Although gossip was viewed as a negative social behavior, Einat and Chen found that gossiping relieves some of the pains of imprisonment. For example, they found that women gossip out of the desire to gain emotional 
support, reduce stress, improve social status, and obtain material benefits. Regardless of the negative or positive benefits of gossiping, women collectively viewed gossiping as an unacceptable behavior.

Both Kruttschnitt et al. (2000) and Greer (2000) suggested that the lack of cohesive relationships among women prisoners may be due to the changing physical environment of modern prisons (e.g., shift from therapeutic homelike cottage system to a controlled dormitory setting). Greer suggested that increased access to the outside world (e.g., visitation, television, and correspondence) and changes in gender roles (i.e., emphasis on individuality vs. social role) influence inside relationships. Greer further suggested that these shifts may explain the challenges of creating supportive relationships and instead contribute to the desire to socially withdraw.

\section{Relational Focused Treatment}

The literature on correctional treatment does not take into account the nature of women's relationships with those in the treatment setting. As illustrated in the above literature, peer relationships among women incarcerated are often hostile and untrusting, yet women are often required to participate in programs with their peers. For example, the current emphasis on providing gender-responsive treatment involves two core principles: creating a safe, respectful environment and creating programs that are relational and promote healthy connections to loved ones and the community (Bloom, Owen, \& Covington, 2003). These principles are grounded in relational theory.

Relational theory is based on the relationship connections that women develop during their life course. Forming trusting interpersonal relationships is the core of the relational model (Covington, 1998; Gilligan, 1982; Miller, 1986). Bloom and Covington (1998) argued that "when a woman is disconnected from others, or involved in abusive relationships, she experiences disempowerment, confusion, diminished zest, vitality and self-worth ..." (p. 12). As described by Covington (2003), the lives of women offenders often consist of "disconnected" and "growth hindering" relationships. Women offenders experience an overabundance of disconnections, including physical and emotional violations in their relationships with others. These disconnections prevent them from becoming self-sufficient and from developing positive selfesteem. Covington (2003) argued that it is the positive connections in women's lives that help them to grow and develop a sense of self-worth.

Research further suggests that women's positive relationships with family, friends, and children may reduce their desire to engage in criminal behavior (Wright, DeHart, Koons-Witt, \& Crittenden, 2013). Other research finds that women are more likely to complete community-based programs if they are reunited with their children (Lichtenwalter, Garase, \& Barker, 2010). Furthermore, research on programs that target women's psychological and physical well-being (including programs that address parenting issues and physical/sexual abuse) shows reductions in recidivism and substance abuse (Tripodi, Bledsoe, Klim, \& Bender, 2011). Although the research is limited on the importance of relationships with program peers, the empirical literature discussed indicates that positive relationships play a crucial role in women's reentry success. 
Recognizing that women prisoners often come from environments that are characterized as abusive, the gender-responsive literature recommends correctional programs create environments that are physically safe, psychologically secure, and where women can develop positive, supportive relationships with others (Bloom et al., 2003; Koons, Burrow, Morash, \& Bynum, 1997). It is within the group setting that women from similar backgrounds can develop strong and empowered relationships. The literature further suggests that group treatment should involve womenonly settings due to the idea that women may struggle to open up and disclose their personal experiences when men are in the room (Bloom \& Covington, 2009). Drawing on the substance abuse literature, we can examine ways to strengthen the relationships among peers in treatment-oriented settings, and why these relationships are so vital to program success.

\section{Therapeutic Engagement and Relationships}

Two important components of a treatment setting, identified in the substance abuse literature, and relevant to the current study, are therapeutic relationships and engagement. According to Broome, Knight, Knight, Hiller, and Simpson (1997), therapeutic relationships entail both the development of supportive bonds between clients and staff, and peer-to-peer connections. Developing strong, supportive relationships with staff and peers is necessary for individual change to occur in a treatment setting (Melnick \& DeLeon, 1999). Furthermore, developing strong relationships with staff and other clients increases treatment retention and reduces substance use (Simpson, 1997).

Treatment engagement involves individual needs, motivation, and program characteristics (e.g., treatment staff attributes, service accessibility, and therapeutic bonding; Simpson, 2001). Simpson further explains that level of treatment readiness determines therapeutic engagement. Welsh and McGrain (2008) defined therapeutic engagement as "a client's active involvement in and commitment to treatment" (p. 272). Research finds that clients with higher levels of therapeutic engagement are likely to remain in treatment (Joe, Simpson, \& Broome, 1998; Simpson, 2001; Simpson, Joe, RowanSzal, \& Greener, 1995), refrain from drug use, and recidivate less (DeLeon, Melnick, \& Kressel, 1997; Simpson \& Joe, 1993).

Therapeutic engagement and relationships are necessary for all types of treatment settings; however, these components are best understood within a TC context. DeLeon (1995) described the components of the TC model with an emphasis on addressing substance abuse, social, and psychological problems through a "community as method" approach. This method involves developing a peer network within the treatment setting where all activities are group-oriented. Other peer components include the use of peer role models as a social learning mechanism, peer encounter groups ("to heighten individual awareness of specific attitudes or behavioral patterns that should be modified"; DeLeon, 1995, p. 11), awareness training (learning how behavior and attitudes affect others in the environment), and emotional growth training (identifying, expressing, and managing feelings). 
Welsh and McGrain (2008) studied the TC dimensions of peer support and counselor rapport as components predictive of therapeutic engagement. They found support for the "community as method" component of the TC model. For example, they measured peer support using items assessing peer relationships and perceptions of treatment group cohesiveness. They found positive peer support, counselor competence, and rapport to be strong predictors of therapeutic engagement. In another study that supports the "community as method" approach, Hiller, Knight, Leukefeld, and Simpson (2002) examined how motivation influences therapeutic engagement in correctional settings. They studied a TC program with a group of male and female probationers. One of the key measures was therapeutic engagement, which included items measuring personal involvement, personal progress, and psychological safety. Of interest to this research is the personal involvement measure, which asked questions about willingness to talk about feelings in the group, and the psychological safety measure assessing perceived level of trust for peers. High levels of psychological safety, and personal involvement, were related to motivation for treatment (i.e., treatment readiness and desire for help; Hiller et al., 2002).

Mosher and Philips's (2006) study on the dynamics of a prison TC program for women looked at the internal dynamics of the program. They found that unruly participants and those less amicable to treatment disrupt the culture of the program. Mosher and Philips found that by removing disruptive residents from the program, overall dynamics among residents and staff improved.

In summary, the research on therapeutic engagement and relationships lends support to the notion that psychologically supportive environments improve motivation, participation, and program outcomes. Prior research on substance abuse treatment with criminal justice populations suggests more research is needed to understand "during-treatment" aspects of a client's experience (Broome et al., 1997), including how peer support plays a role in increasing therapeutic engagement (Welsh \& McGrain, 2008). Research on the social environment within female prisons sheds light on some of the challenges associated with creating a supportive environment with this population. To understand these relationships, the social context of a community correction setting is examined. Specifically, this qualitative study examines three core research questions:

Research Question 1: How do women get along with other residents in the halfway house?

Research Question 2: How do they perceive on-site group treatment groups?

Research Question 3: How do they perceive off-site group treatment programs?

The following sections provide details on the methodology used, a description of the study sample, and an overview of the halfway house program. The "Results" section introduces themes related to the core research questions. The article concludes with a discussion of findings, study limitations, and recommendations for improving group treatment for women in correctional settings. 


\section{Method}

\section{Data Collection}

Permission to conduct research at the halfway house site was approved by the director of the facility and the Institutional Review Board at John Jay College of Criminal Justice. All women residing at the halfway house between June 2007 and November 2007 were eligible to participate in this study. The researcher selected to interview any resident present at the halfway house during the hours the researcher was on-site. To reach all potential participants, the researcher visited the halfway house during the day, afternoon, and on many evenings. Caseworkers used a daily roster to determine which residents were on-site. Once several residents were identified, the caseworker, or other halfway house staff, would call them down one by one and send them to the location of the interview space. During the day, interviews often took place in a private classroom space where group treatment was held. During the evening, the interviews took place in the case manager's office after she left for the day. Both spaces had a door that was closed during the interview. When a resident entered the interview space, the researcher introduced the study and consent process. The researcher informed participants about the voluntary nature of the interview, and that confidentiality would be protected. After women agreed to participate, the researcher asked for further permission to audio record the interview.

Forty-three women were residing in the halfway house on the day of the first interview. Over a 6-month period, 35 women were conveniently selected to be interviewed; however, only 33 agreed to participate. Four of the 33 women refused to have the interview recorded. The in-depth qualitative interviews lasted between $45 \mathrm{~min}$ and two hr. Each interview was structured around a series of broad questions on women's pathway to prison, their experience at the New Jersey Department of Corrections (NJDOC), the transition to the halfway house, daily life at the house, addressing reentry needs (e.g., job searching, housing, family reunification, treatment for substance abuse and mental health, etc.), family and peer relationships, and expectations for reentry to the community. All recorded interviews were transcribed by the researcher. The researcher took detailed notes during the four interviews where participants refused to be recorded.

In addition, demographic, criminal history, and family history data on the sample population were collected from resident case files. Data from case files included PreSentence Investigation Reports, the NJDOC Comprehensive Assessment Profile, a Correctional Facility Assessment, and the Level of Service Inventory-Revised (LSIR) conducted by halfway house staff. These documents were used to develop a profile for each participant.

\section{Analysis}

As the interviews covered a wide range of topics, the researcher identified subsections of the transcripts where respondents specifically spoke about on-site group treatment programs, off-site treatment, and interactions with residents. A process of initial 
coding then took place as a method of studying fragments of transcripts (Charmaz, 2006). As segments of transcripts were labeled, the researcher analyzed the meaning of the participants' words by writing analytical memos (Strauss \& Corbin, 1998). Codes developed during initial coding were applied during the second analytical phase of focused coding. During this phase, the qualitative software program, ATLAS.ti, was used to aid in making connections between interviews and to search for additional themes related to women's perceptions of the halfway house experience. This phase allowed the researcher to further identify aspects of the data that may have been overlooked during initial coding and also allowed for greater comparison between participants (Charmaz, 2006). Last, to develop a sample profile, the researcher reviewed case files and analyzed the data using descriptive statistics related to demographic, criminal history, and family variables. Profiles were created to develop an overall sample profile of participant characteristics (see the following section). Profiles were also used to provide further context to women's experiences and perceptions of group treatment.

\section{Sample}

The average age of interviewees was 39. Women were primarily African American (52\%), followed by $27 \%$ White and $21 \%$ Hispanic. More than half of the sample was unmarried (61\%), and the majority had at least one child under the age of $18(64 \%)$. Sixty-one percent of the participants had a high school diploma or general education development (GED), yet $55 \%$ were frequently unemployed prior incarceration. The majority of the sample had an extensive criminal history with $58 \%$ having three or more criminal convictions. Sixty-four percent of the sample had a history of substance use; however, only $49 \%$ had a current substance abuse problem. An indication of a mental health problem was less frequently identified. Twenty-four percent of the sample reported receiving previous mental health treatment. In addition, $46 \%$ experienced domestic violence and $30 \%$ were sexually abused in their childhood.

\section{The Setting}

The overall mission of the halfway house was to provide a range of interventions to reduce reoffending, enforce accountability, and promote public safety. Residents entered the halfway house with a range of needs, including substance abuse, mental health, physical and/or sexual abuse, and limited employment histories. The program is considered holistic in the sense that all needs are identified and treatment plans are developed to address individual needs.

The halfway house follows a gradual phase system that provides residents with privileges as they achieve certain goals and maintain good standing in the program. Program objectives include attending job readiness class, participating in mandatory on-site treatment groups, obtaining and maintaining employment or education, and following other goals outlined on individualized treatment plans. To help residents achieve their individual treatment goals, staff requires eligible residents to participate in an on-site substance abuse and gender-responsive treatment groups. In addition, residents receive 
individual life skills coaching, employment assistance, and case management services. Women in need of additional services, such as mental health, domestic violence counseling, and parenting, are referred to outside programs in the local area.

During the data collection period for this study, the halfway house offered a genderresponsive treatment group, an on-site substance abuse group, weekly on-site Alcoholics Anonymous meetings, and outside opportunities to attend Narcotics Anonymous (NA) groups or outpatient treatment. Fourteen participants were engaged in some type of drug treatment - including 8 enrolled in the mandatory on-site group. Nine different participants were enrolled in the mandatory on-site gender-responsive group. Participants in the gender-responsive group had no history of substance use or had a lengthy history of sobriety. The gender-responsive group focused on family issues, relationships, and problem-solving and communication skills. Women learned skills to cope with high-risk situations, how to build upon personal strengths, and were encouraged to develop healthy support networks and community resources. Observations of these groups, and participants' perceptions of them, are discussed in this article.

\section{Results}

Six major themes emerged during the analysis of interview transcripts and observational field notes. The six themes identified include (a) trust and avoidance, (b) negative treatment perceptions, (c) repetitive and irrelevant treatment, (d) positive treatment perceptions, (e) desire for outside treatment, and (f) benefits of outside treatment.

\section{Trust and Avoidance}

Participants in this study all came from the same correctional facility after serving varying terms of incarceration. Within the first few days of arriving at the halfway house, women described feeling a heightened sense of physical and psychological safety within the confines of the facility. The majority developed therapeutic connections with halfway house staff. Residents perceived staff as supportive, trustworthy, caring, and effective (see Cantora, Mellow, \& Schlager, 2014). Relationships with residents, however, lacked cohesion and were generally non-supportive. This section highlights the challenges women had trusting other residents.

The majority of residents have been living with other incarcerated women for long periods of time (for some, several years) and felt that the residents at halfway house were the "same" type of women from prison. According to one participant, "They still have their attitudes. Everybody's still got their guard up, you know, nobody trusts anybody. It's the same." Another participant stated, "I just tolerate most of them. I get along with some of them. You still have the same tension and craziness [as prison]. You'd think being here would alleviate some of it." The fact that women were in a less restrictive environment, with opportunities to prepare for reentry, did not seem to change the lack of trust or tension in the environment. For women who have been through the system multiple times dealing with other women was part of the experience. 
Sometimes I get to a point where I can't stand being around women. One thing that I think is good about it for me [being around women for so long] - like I think it's easy for me to deal with because of my attitude. Rather than someone who has never been in prison-I think sometimes it really gets to me being around all these women and their attitudes, the hollering and screaming. I don't know I just deal with it. (Amy)

Another resident, Carol, described not wanting to develop relationships with other residents due to trust issues: "When I go home I had relationships with women and men, I can talk more. But a place like this no. You can't trust people here. Cause always someone has a motive." April also described her general mistrust of women as the reason for her unwillingness to discuss personal problems when other women are present. For April, disclosure meant the risk of someone gossiping about her. She described her anger as a major trigger and worried about being in a vulnerable situation that would test her anger.

I don't like women, I don't be around women in the street and it was like me sitting there with all these women. I didn't want to (open up) cause women like to talk - they gossip. I just felt like opening up some of my personal issues with strangers-I have an anger problem, so for me to hear someone talking about something I might have said that is a trigger. Why should I subject myself to the arguments? I am very short tempered.

Participants described wanting to take care of their own lives and did not want to associate with others-"I just do what I need to do for me and I stay focused." Participants often described keeping to themselves and avoiding conflict with others. Avoidance by not speaking, or associating, with confrontational residents was a common response. As was the case with many residents, avoidance of others was the result of lack of trust and the desire to "just go home."

Avoiding residents was more challenging to do in the halfway house than in the prison setting. Participants had more privacy in prison because sleeping accommodations were limited to sharing with one other person, whereas in the halfway house, several women roomed together. Similar to prison, residents developed ways to avoid other women including listening to music, reading, and watching television. This avoidance behavior is similar to what other researchers have found (Kruttschnitt et al., 2000; Owen, 1998).

When asking the following participant about recommendations for additional programming at halfway house, Linda suggested developing a program to help residents deal with the social aspect of the halfway house.

They should have more programs. There are a lot of attitudes and I think we need other groups. Some women are really mentally disturbed. Some are scared to get out and they should talk about their fears. There's not enough time to share with one another and ask about our day. They are always at each other's throats, they steal from each other, they are still doing the same stuff-women don't want to talk about it. We have Monday night government groups - but people shut down and don't want to talk about house problems, they feel like they are snitching. 
Linda described the general lack of trust among residents. She suggested developing an open forum where women can talk about both personal issues and problems that occur within the house as a way to potentially eliminate the negative tension. Overall, findings from observations and interviews indicated that residents did not trust the majority of women in the house. Surprisingly, many participants were able to form relationships with one or two other residents (see Cantora et al., 2014). These relationships were often formed during their incarceration. Regardless of these connections, the majority described an environment that lacked cohesion and trust.

\section{Negative Treatment Perceptions}

During the time period this study was conducted, two mandatory treatment groups were offered inside the halfway house. Based on individual needs, women were enrolled in either the 3-month substance abuse or gender-responsive program. To understand how women perceived these groups, the researcher asked several questions about their participation. Women were asked to discuss what programs they participated in, how they perceived the curriculum, whether the group was helpful in addressing their needs, and how the group might be improved to better meet their needs. In addition to interviewing women about their group experience, the researcher observed both groups over the course of 3 months.

During observations of both mandatory on-site groups, several residents expressed boredom, many barely participated, and when participating did so at a superficial level - meaning their participation during group sessions did not appear genuine. Many women simply participated in the groups because they were mandated to do so. For example, two women in the substance abuse group were observed rolling their eyes when other residents shared their experiences, and they occasionally made negative statements out loud to the entire group. During interviews, both participants discussed aspects of the group they disliked. They perceived the group as too "educational" and "boring," too overpowered by certain women who controlled group discussions, and interfered with their jobs. Debbie openly stated that she did not want to participate in treatment because she was not "looking for help." She also did not want to hear other women disclosing their "war stories."

No, I could care less, to be honest. I'm just doing it because I have to. I'm not looking for help. And none of us really want to hear it neither. Like everybody in there really just wants to get it over with, so none of us are really there for listening to anybody's war stories or anything like that, you know what I mean? It's just like just be quiet and answer the questions and get it over with. That's pretty much how we're doing it. (Debbie)

Debbie did not pursue treatment outside the halfway house, and instead was more interested in working and saving money for release. Kate, who had similar perceptions as Debbie, attended NA groups in the community.

I hate that class. I don't hate the class but there's just certain people in there irk me to death. I mean, just shut-up. I don't need to know about your friends, mothers, fathers, 
sisters, brothers. You know, it's the residents, two in particular. And it drives Ms. [instructor] crazy, too, and you can see it but she can't say just shut-up! You know what I mean, so-It's not very professional. I can but she can't. (Kate)

Another resident, Carol, who expressed boredom during group sessions was asked how she felt about group treatment. She struggled with her response to this question, shrugged her shoulders, rolled her eyes, and sarcastically responded:

It's good. It's fun. It's good to get out of here. I like walking from here to there.

It's new. I learn coping, life skills. I don't know. Everything I learn. I don't know ... there are things that are helpful. (Carol)

Carol, a resident who served 15 years in prison, did not seek out outside treatment while at the halfway house. She explained that she enjoyed leaving the halfway house to attend the group. The group was held several doors down from the halfway house in a building that housed the program's administrative offices. Carol looked forward to the opportunity to get fresh air and have a quick cigarette.

\section{Repetitive and Irrelevant Treatment}

Several women in the on-site substance abuse group perceived the groups as repetitive to other programs they participated in prison or other community settings. A common response was, "I've heard this all before." Three women in the gender-responsive group identified specific components of the group that were unrelated to their needs"I don't have that problem." For example, older participants, and those with strong family connections, perceived the family module as irrelevant to their lives. Although the curriculum was designed to address common issues experienced by women prisoners, not all women shared similar problems and/or experiences (e.g., family and relationship problems).

It's not beneficial. I mean those things that they are talking about establishing I already do. I work, I have contact with my kids, even though they don't come and visit I keep contact with them all the time. I take care of my kids financially. I just paid for my son, I just paid for his college books and I sent my brother 300 dollars for him to buy school clothes and things. I am still being the productive parent I would be in the community, but I am doing it in here. (Stacy)

Jenny, a resident with a long history of substance abuse, completed a TC program while incarcerated. She expressed frustration with having to participate in another drug treatment program. Although she was dissatisfied with the on-site group treatment program, she attended NA groups in the community.

It's alright [on-site drug treatment], it's ... things that I have heard over and over and over again. But it's alright I am going to participate and I am going to be there. And it's going to 
... ya know I don't know everything so there is always something to learn. And that's the attitude I have to keep. It's frustrating to write the same story over again. My story is not going to change. I've been writing my story since 2005, it's not going to change. (Jenny)

Monique, who also attended outside NA groups, shared a similar perception:

You could never have enough knowledge. You know what I am saying. The other day we touch on a lot of good things. But basically I've been through all this. I am just ready to go. I went through this over and over and over again. But still like I said, there still might be something to see that I can grab onto and keep it. So, the program is good. You know? I could have never experienced going to a program, never had the chance to you know experience what I did, it is what it is . . it's a good program to have. And like I said you could never get enough knowledge, I mean there might be something I missed somewhere else that I can grab here. (Monique)

Both Jenny and Monique were positive in their comments about on-site drug treatment. Several women who have been through treatment programs prior to the halfway house viewed the halfway house substance abuse group as repetitive but acknowledged that there was "always something to learn." A maintenance program, such as Narcotics and Alcohol Anonymous, may better fit their treatment needs.

\section{Positive and Helpful Treatment}

Several women discussed positive aspects of the on-site treatment groups. Marie, a 44-year-old woman with a lengthy criminal history, has participated in a variety of different drug treatment programs in the past. Marie highlights the positive aspects of the drug treatment group, including her ability to connect well with the group instructor and the size of the group. She also identifies the reasons others in the group may not enjoy it as she does.

I love it. It's not just like a group where you can talk. They teach you about each drug and what it does. It makes you aware of what you put in your body. Everybody has their own way of bringing it and Ms. M (instructor) is very awesome. She makes you want to do it. And it's a small group. Other groups are always so big . . . if you have something to say she'll let you, but for the most part most people just want to come in and get it done, because most of them work. It's the evening, you've had a hard day, or they're getting ready to work the night shift, or it's their only day off and it's being interrupted.

Another resident, 19-year-old Annie, described receiving positive feedback from others in the drug treatment group. Annie was the only participant who described her peers as "family." Annie's positive experience may be attributed to the fact that most of her peers were much older (average age 39), and her exposure to the adult system was relatively new. Although she felt comfortable talking in the group setting, she will not engage in the same type of dialog with her group members in the common living areas of the halfway house. 
Feels like family - I've grown to love my group, I talk to the ladies only when in group not in room. It's my chance to open up and it took me a little while getting a lot of feedback from everyone. In the room upstairs I play around with the girls but will not sit down and talk to them like in group. (Annie)

Both Marie and Annie did not participate in off-site treatment groups. Another participant with positive views of the gender-responsive group struggled with the idea of opening up in the group setting. Ella discussed keeping her abusive relationship a secret from her family but recognized that talking about it may reduce some of her internal anger. She participated in the group but struggled to disclose her "secret."

We just went through abusive relationships now. It is touchy. Cause you are sitting in a group. And this is my secret - this is something I hold in. Family don't know, nobody knows. But I might let it out cause it has a lot to do with my anger. Just a lot that has to do with me. I talk a little bit [in group], but not too much. I was in a relationship for four years and I am not ready to open up to a group of people ... it's just me.

At the time the interview was conducted, Ella was in the process of searching for a domestic violence group in the community. Most of the women interviewed were interested in, or already attending, outside treatment. Regardless of their outside treatment participation, or their desire to attend alternative programs, they were still required to attend the on-site groups. They understood that attending mandated onsite groups was part of the halfway house requirements. They attended, responded when addressed, and minimally participated. There was a variety of women in these groups - those who were clearly defiant by their under-the-breath comments and facial expressions, those who remained silent, and those who overpowered the group dialog. Although many participants identified negative aspects of the groups, as illustrated above, some participants were able to benefit from the content of the groups.

\section{Desire for Outside Treatment}

The relationship dynamics within the halfway house led to many women desiring treatment away from the house. This was true for women in need of substance abuse treatment, as well as women seeking mental health and victimization services. Stacy, for example, was pro-active in the search for outside treatment and found a local women's group that provided both individual and group counseling. Her desire to receive treatment outside the halfway house came from years of harassment by other incarcerated women. Having worked in a profession that was not respected by other women in prison, Stacy sought treatment outside the halfway house.

I go to a women's group now that is in I go once a month. I found that group myself. And I talk to the lady and she helps boost my self-esteem and we talk about different issues but, that is better because it is in a private setting and nobody there knows I am 2 
This quote illustrates the connection between building self-esteem and forming a therapeutic alliance that allows women to feel comfortable talking about problems. Stacy was unable to open up in the on-site gender-responsive group because she perceived the social environment as threatening. Other residents also discussed wanting treatment outside of the halfway house because they found it difficult to disclose personal information in on-site groups. Participants, like Ella, discussed not being "ready" to disclose their past to others and expressed concern with other residents' ability to keep their personal stories within the group setting. The connection between wanting private treatment and not trusting other residents is illustrated in the following passage:

I wanted something separate from here. To get away for the elements of here, of the girls and I didn't want anyone in my business. See we all . . you have to know about people and girls. Not only here ... they are catty. And at different times, they may be your friend today and tomorrow they might be biting your back. And once you're in therapy with people it's what is said in the room does not stay in the room. No, that doesn't work. They don't respect people like that. So, that is why I do not want you to be in therapy with me. That's why I want my own therapy. I want it private. (Phyllis)

Phyllis, a resident with an extensive history of abuse, drug use, and mental health problems, described wanting private therapy because she did not trust other residents. The researcher continued to ask Phyllis about attending treatment with women at the halfway house. To Phyllis, residents at the halfway house were emotionally harmful toward one another, which made opening up in the groups too risky. "It's all made out of hurt and emotions here. It's a cancer. Everyone is stepping on each other to get up. Let me step on you so I can get higher." Regardless of where the group was located, some women were unwilling to disclose their "secrets" in a public domain. Many women, however, voluntarily sought out individual and group treatment not affiliated with the halfway house.

\section{Benefit of Outside Programs}

One of the most prominent findings from asking women about participating in services outside the halfway house were the multiple benefits of going to non-halfway house programs. Women did not describe anything negative about the services and treatment they received outside the halfway house, and appeared to be more responsive to these services. The most common type of treatment attended off-site were coed 12 -step groups (i.e., Narcotics and Alcoholics Anonymous). Women described attending these groups to learn about community resources, develop new pro-social associations, escape the halfway house environment, hear stories for motivation, and meet men for sexual gratification.

When asking participants about attending outside 12-step groups, several discussed a recent incident at an NA group held at a local church. Some participants responded that "something happened" but would not elaborate on why the meetings were canceled. Others overtly stated that residents were engaging in sexual activity with men at the 
meetings. "When I got here it seemed like they had this problem that all the girls going to meet the men. I don't know if you know, one of the girls had this sexual thing so they stopped that." Once the halfway house learned of the incident, they prohibited residents from attending meetings at the church. Residents did, however, continue to attend meetings at other locations throughout the community. Although correctional program administrators may perceive this incident as a negative consequence of sending women to outside treatment, there were many positive benefits discussed during the interviews.

Several participants discussed the value of networking with people in recovery. One resident, estranged from her family, discussed looking forward to returning to her hometown 12-step meetings where she would see her old peers. This group of peers was her only support system. Another participant, Kate, discussed using community NA meetings to meet new pro-social peers.

I think meetings are helpful, because not only are they helpful but you're sharing yourself with people who are clean and you start to hang out so, you know, you start doing your thing. I'm not going to go to meetings and then come down here and hang out with people at the transportation center. ${ }^{3}$ I'm going to go to meetings and meet new people.

In addition to forming friendships, networking with other group members helped participants learn about community resources. Beth was able to secure transitional housing after informing her 12-step group members that she was searching for a place to live.

And I shared in group one day, there were like 80 people around but I don't care I need to get something off my chest. And you get feedback from people, sometimes you get a bunch of jerks, sometimes you get good feedback. So I shared that . . you know most people know I am from the facility around the corner and my time is getting short and I don't want to go back to where I came from, I want to stay in this town and keep my job. After group she came to me and said "yo let me tell you about this program." (Beth)

When asking participants about the type of services or programs they would have liked to receive while residing at the halfway house, they frequently suggested more on-site and community 12 -step groups. The fact that many participants with drug histories voluntarily attended these groups and requested the halfway house to provide more opportunities to attend 12-step groups implies that they "wanted" to participate in drug treatment. Whether their participation was to develop new pro-social relationships, learn about community resources, meet others for sexual gratification, hear stories for motivation, get feedback from people similar, or to just get away from the "chaos" of the halfway house, off-site groups were the most desired treatment.

\section{Discussion}

This study examined women's experiences at a community correction facility in New Jersey. Peer dynamics and engagement in on-site and off-site group treatment were discussed. 
Similar to other research (Einat \& Chen, 2012; Greer, 2000; Severance, 2005), most participants struggled to trust other residents and avoided social interactions. The dynamics of resident relationships made it difficult for women to engage in on-site group treatment. The lack of group cohesion and the desire for private treatment were two of the main reasons participants wanted individual or group treatment in the community. Participants also described the on-site groups as not meeting their needs, too educational, boring, and unhelpful. There were a few, however, who perceived the groups as useful to addressing their needs. The fact that many women were unresponsive to on-site groups but participated in programs off-site suggests that residents were not unresponsive to group treatment in general, but rather that their unresponsiveness was attributed to the programs delivered inside the halfway house. Mandatory group treatment with women who have been incarcerated with each other for a long timewomen perceived as "chaotic" and untrustworthy - was unappealing to most participants. As long as the treatment was away from the house, women were open to it and sought it out. Women desired to be in a setting where no one knew them, to meet new non-incarcerated people, and to have the opportunity to speak about problems without fear of disclosure.

Although the findings from this study are important in understanding women's experience in treatment settings, there are some limitations. Due to the small sample size and nature of data collection, this method does not allow for generalizing findings to other female community correction programs. The researcher also did not ask program staff or administrators about resident relationships or their perceptions of on-site group treatment. Another limitation of this study was the lack of off-site treatment group observations. Observing off-site NA groups attended by halfway house residents would have generated a comparison between on-site and off-site group treatment engagement. Gathering these data is something that should be collected in the future to generate a global understanding of the context of community correction programs, and how women respond to different treatment environments (e.g., mandatory on-site vs. voluntary off-site). Regardless of these limitations, the study's findings support the notion that peer relationships play an important role in women's experiences inside community correction programs.

A major question remaining from the findings of this study is, "Would women be more amenable to on-site treatment if the dynamics among residents were more supportive?" Findings suggest that the internal dynamics affected residents' ability to trust others, which may have indirectly resulted in the desire for outside group programming with people outside their social and familial network. Evidence from the substance abuse literature suggests that peer support and "community as method" are factors that contribute to treatment motivation (Hiller et al., 2002; Welsh \& McGrain, 2008). The gender-responsive literature also supports this finding by emphasizing the importance of creating therapeutic environments within correctional programs. Improving the social environment of female residential correctional programs to follow the principles of gender-responsive treatment, and TC models, is something program developers and administrators need to seriously consider. In community correction settings, where clients already know each other 
from their prison stay, pre-group skills training may be beneficial. Skills training where clients learn to trust their peers, and staff, to develop therapeutic relationships with them may improve the on-site group experience. Otherwise, clients with trust issues, and other interpersonal difficulties, will not benefit from this type of group setting and may pose a risk to the entire group process (MacNair \& Corazzini, 1994).

However, considering the nature of the relationships among incarcerated women, creating such an environment in a community setting may be rather challenging. As illustrated in this study, and supported by the research on the nature of women's prison relationships, women have already come to "know" their peers while incarcerated. Shift in environment, regardless of therapeutic design, may not change how women perceive their peers, their ability to trust them, or where they desire to attend treatment. It is important for program administration to recognize conflict among clients before mandating them to on-site treatment groups. To understand, and measure, how women perceive the program setting, administrators should consider conducting an assessment of the social climate. This would include measuring women's level of trust, treatment readiness, interest in on-site treatment, and concerns about participating in groups with other residents. Identifying specific client concerns would allow administrators to determine the value and benefit of providing on-site groups and, if conducive, develop ways to improve the overall social climate within the setting.

In addition to the social climate of a treatment setting affecting participation, being required to partake in a group irrelevant to perceived needs will also create resistance. Correctional programs sometimes require clients to participate in "one-size-fits-all" treatment groups. As illustrated in this article, this approach to treatment is problematic. Participants in this study were mandated to attend treatment groups that did not always address their perceived needs. These women identified community programs that better fit their needs.

If the social climate is threatening to the group process, and/or the group is irrelevant to women's needs, then treatment alternatives may need to be considered. In this case, enhancing individual treatment opportunities and/or off-site group programs may be warranted. Although the benefit of providing on-site group treatment allows administrators to monitor client progress, deliver adequate treatment, and supervise clients, the presence of a negative social climate may not be worth these benefits. However, off-site treatment prevents program staff from monitoring client progress, treatment quality, and clients' whereabouts. These drawbacks may prevent many community correction programs from utilizing off-site treatment. However, as illustrated in this study, connecting clients to community service providers and non-incarcerated clients had multiple benefits. As a reentry strategy, outside treatment may actually be the smarter approach.

\section{Declaration of Conflicting Interests}

The author(s) declared no potential conflicts of interest with respect to the research, authorship, and/or publication of this article. 


\section{Funding}

The author(s) received no financial support for the research, authorship, and/or publication of this article.

\section{Notes}

1. Relationships formed based on traditional family roles. These roles include mother, father, sister, brother, grandmother, and so on.

2. To protect this "Stacy's" identity, the researcher eliminated parts of the quote stating her previous occupation.

3. Participants described the transportation center as a place where drug users hang out.

\section{References}

Andrews, D. A., \& Bonta, J. (2010). The psychology of criminal conduct (5th ed.). Newark, NJ: LexisNexis.

Bloom, B., \& Covington, S. (1998, November 11-14). Gender-specific programming for female offenders: What it is and why it is important? Paper presented at the 50th annual meeting of the American Society of Criminology, Washington, DC.

Bloom, B., \& Covington, S. (2009). Addressing the mental health needs of women offenders. In R. Gido \& L. Dalley (Eds.), Women's mental health issues across the criminal justice system (pp. 160-176). Saddle River, NJ: Prentice-Hall/Pearson.

Bloom, B., Owen, B., \& Covington, S. (2003). Gender-responsive strategies: Research, practice and guiding principles for women offenders. Washington, DC: U.S. Department of Justice, National Institute of Corrections.

Broome, K. M., Knight, D. K., Knight, K., Hiller, M. L., \& Simpson, D. D. (1997). Peer, family, and motivational influences on drug treatment process and recidivism for probationers. Journal of Clinical Psychology, 53, 387-397.

Cantora, A., Mellow, J., \& Schlager, M. (2014). What about nonprogrammatic factors? Women's perceptions of staff and resident relationships in a community corrections setting. Journal of Offender Rehabilitation, 53, 1-22.

Charmaz, K. (2006). Constructing grounded theory: A practical guide through qualitative analysis. Thousand Oaks, CA: Sage.

Covington, S. (1998). The relational theory of women's psychological development: Implications for the criminal justice system. In R. Zaplin (Ed.), Female crime \& delinquency: Critical perspectives \& effective interventions (pp. 113-131). Gaithersburg, MD: Aspen.

Covington, S. S. (2003). A women's journey home: Challenges for female offenders. In J. Travis \& M. Waul (Eds.), Prisoners once removed (pp.67-103). Washington, DC: Urban Institute.

DeLeon, G. (1995). Residential therapeutic communities in the mainstream: Diversity and issues. Journal of Psychoactive Drugs, 27, 3-15.

DeLeon, G., Melnick, G., \& Kressel, D. (1997). Motivation and readiness for therapeutic community treatment among cocaine and other drug abusers. American Journal of Drug and Alcohol Abuse, 23, 169-189.

Einat, T., \& Chen, G. (2012). Gossip in a maximum security female prison: An exploratory study. Women \& Criminal Justice, 22, 108-134.

Gehring, K. S., Van Voorhis, P., \& Bell, V. (2010). "What Works" for female probationers. An evaluation of the moving on program. Women, Girls, \& Criminal Justice, 11(1), 6-10. 
Giallombardo, R. (1966). Society of women: A study of a women's prison. New York, NY: Wiley.

Gilligan, C. (1982). In a different voice. Cambridge, MA: Harvard University Press.

Greer, K. (2000). The changing nature of interpersonal relationships in women's prisons. The Prison Journal, 80, 442-468.

Hiller, M. L., Knight, K., Leukefeld, C., \& Simpson, D. D. (2002). Motivation as a predictor of therapeutic engagement in mandated residential substance abuse treatment. Criminal Justice Behavior, 29, 56-75.

Joe, G. W., Simpson, D. D., \& Broome, K. M. (1998). Effects of readiness for drug abuse treatment on client retention and assessment of process. Addiction, 93, 1177-1190.

Jones, R. S. (1993). Coping with separation: Adaptive responses of women prisoners. Women \& Criminal Justice, 5(1), 71-97.

Koons, B. A., Burrow, J. D., Morash, M., \& Bynum, T. (1997). Expert and offender perceptions of program elements linked to successful outcomes for incarcerated women. Crime \& Delinquency, 43, 512-532.

Kruttschnitt, C., Gartner, R., \& Miller, A. (2000). Doing her own time? Women's responses to prison in the context of the old and the new penology. Criminology, 38, 681-718.

Lichtenwalter, S., Garase, M. L., \& Barker, D. B. (2010). Evaluation of the house of healing: An alternative to female incarceration. Journal of Sociology \& Social Work, XXXVII(1), 75-94.

MacNair, R. R., \& Corazzini, J. G. (1994). Client factors influencing group therapy dropout. Psychotherapy, 31, 352-362.

McRoberts, C., Burlingame, G. M., \& Hoag, M. J. (1998). Comparative efficacy of individual and group psychotherapy: A meta-analytic perspective. Group Dynamics: Theory, Research, and Practice, 2, 101-117.

Melnick, G., \& DeLeon, G. (1999). Clarifying the nature of therapeutic community treatment: The Survey of Essential Elements Questionnaire (SEEQ). Journal of Substance Abuse Treatment, 16, 307-313.

Messina, N., Grella, C., Cartier, J., \& Torres, S. (2010). A randomized experimental study of gender-responsive substance abuse treatment for women in prison. Journal of Substance Abuse Treatment, 38, 97-107.

Miller, J. B. (1986). Toward a new psychology of women. Boston, MA: Beacon Press.

Mosher, C., \& Philips, D. (2006). The dynamics of a prison-based therapeutic community for women offenders: Retention, completion, and outcomes. The Prison Journal, 86(6), 6-31.

Owen, B. (1998). "In the mix": Struggle and survival in a women's prison. Albany: State University of New York Press.

Propper, A. M. (1982). Make-believe families and homosexuality among imprisoned girls. Criminology, 20, 127-138.

Severance, T. A. (2005). "You know who you can go to": Cooperation and exchange between incarcerated women. The Prison Journal, 85, 343-367.

Simpson, D. D. (1997). Patient engagement and duration of treatment (Unpublished Paper funded by National Institute on Drug Abuse, Grant No. R01DA06162). Fort Worth: Institute of Behavioral Research, Texas Christian University.

Simpson, D. D. (2001). Modeling treatment process and outcomes. Addiction, 96, 207-211.

Simpson, D. D., \& Joe, G. W. (1993). Motivation as a predictor of early dropout from drug abuse treatment. Psychotherapy, 30, 357-368.

Simpson, D. D., Joe, G. W., Rowan-Szal, G., \& Greener, J. (1995). Client engagement and change during drug abuse treatment. Journal of Substance Abuse, 7, 117-134. 
Strauss, A., \& Corbin, J. (1998). Basics of qualitative research: Techniques and procedures for developing grounded theory. Thousand Oaks, CA: Sage.

Tripodi, S. J., Bledsoe, S. E., Klim, J. S., \& Bender, K. (2011). Effects of correctional-based programs for female inmates: A systematic review. Research on Social Work Practice, 21, 15-31.

Ward, D. A., \& Kassebaum, G. G. (1965). Women's prison: Sex and social structure. Chicago, IL: Aldine.

Welsh, W. N., \& McGrain, P. N. (2008). Predictors of therapeutic engagement in prison-based drug treatment. Drug and Alcohol Dependence, 96, 271-280.

Wright, E. M., DeHart, D. D., Koons-Witt, B. A., \& Crittenden, C. A. (2013). "Buffers" against crime? Exploring the roles and limitations of positive relationships among women in prison. Punishment \& Society, 15, 71-95.

Wright, E. M., Van Voorhis, P., Salisbury, E., \& Bauman, A. (2009). Gender-responsive prisons: Lessons from the NIC/UC gender-responsive classification project. Women, Girls, \& Criminal Justice, 10, 81-96. 